\title{
The Training for Special Education Schools' Physical Education Teachers in Chongqing
}

\author{
Jinxia Bao, Xiaoling Huang \\ Southwest University sports institute, Chongqing 400715, China \\ huzhicheng0504@126.com,804422610@qq.com
}

\begin{abstract}
This paper takes the situation of the training for sports teachers in Chongqing' special education schools as the object. It focuses on three aspects of the content, including the cultivation actuality of special education sports talents and the orientation and in-service training for special education schools' sports teachers. The results are showed as follows: The level of the training integration for special sports teachers is not high; The cultivation of special sports talents, namely the pre-service training, is in the supply and demand contradiction; The orientation for special sports teachers is of overgeneralization; The depth of the in-service training is not enough. Then after consulting literature, visiting experts and discussing with scholars, we summed up the following suggestions: Offer special physical education curriculum in Chongqing' normal universities and sports colleges; Reform orientation system, optimize the evaluation scheme for new teachers; Deepen the level of in-service training, provide opportunities for teachers' off-job learning; In policy and funding support, enhance the level of integration of teachers' vocational training.
\end{abstract}

Index Terms - Chongqing, Special education, PE teacher, Training

\section{Introduction}

Special education sport is an important part of school sports. To special children, physical education not only has the function to help them defect compensation and adapt to the society, but also be of great significance to stimulate students' potential and promote their personalized development. Interim Provisions of special schools and sports law explicitly pointed out: "special education schools should implement the national education policy, according to students' physical and mental characteristics and the actual need for education", "schools should create conditions for disabled student to organize sports with their features activities"[1]. This requires physical education teachers to master the teaching skills for the disabled, to accept professional cultivating and training and to be equipped with professional qualities adequately.

\section{The Object and Methods}

\subsection{The object}

The study selected physical education teachers and the leaders who are in charge of special schools' sports work as the investigation object. At the same time, this article investigated the professional teachers and classmates of special education from Southwest University and Chongqing Normal University.

\subsection{The methods}

This article mainly adopted methods of questionnaire and interview to obtain information. The questionnaire was conducted for physical education teachers in special schools. The amount of the questionnaire was 44 and recycled 42 , the rate was $95.5 \%$.

\section{The results and analysis}

\section{1 pre-service training for special education sports talents}

In 1972, "James report" put forward a new plan about teachers' pre-service education and post-career education. It formed a continuum of the training which was split into three stages as accepting higher education, pre-service professional training and in-service education [2]. The training for Chongqing special sports talents, from the perspective of teachers to accept higher education, mainly comes from professionals of special education and physical education graduates.

\subsubsection{The training for special education professionals}

Southwest university and Chongqing normal university are the only two schools in Chongqing which set up the profession of special education. The major courses for undergraduates mainly include special education physiology, diagnosis and assessment, special children's communication (sign language, Braille, lexis equips) etc. The curriculum system involved sports were mainly about ball games, tai chi, aerobics, etc. But is the sports knowledge and skills enough for physical full-time or part-time teaching? Comparing the subject setting for special education and the setting for Tianjin' special sports education, one of the earliest professions about special sports, the latter helps students understand sports more fundamentally. Because it not only contains the special education technology, the special children's pathology, also includes the special children's sports games, the disabled sports and rules etc.

\subsubsection{The training for sports professionals}

By collating, Chongqing runs a total of eight schools which have opened sports undergraduate professional. Chongqing Liberal Arts College is the only one which has set up social sports (health rehabilitation direction) and others direct for education and training. For the courses to rehabilitation, Chongqing Liberal Arts College opened the fitness theory and method, acupuncture, massage, nutrition, etc 15 professional classes. However, other schools set sports anatomy, sports health care etc 4-5 courses. But the results showed that, whether physical education or health cares professional graduates, just a few go to the way for special sports teaching. The mainly reason may be that pure sports 
specialized students exist awareness and the language barrier in a large degree.

\subsubsection{The supply and demand for special sports talents}

When special schools introduce special physical education teachers, they always focus more attention on two sides: health rehabilitation theory and practice, sports teaching skills, giving priority to former. Detailed to it, it is about exercise physiology acupuncture, physical health, rehabilitation, etc. To see their demand, 20 special schools surveyed, each school has 2-3 sports teachers commonly, and eighty-five percent is two. Setting districts of Beibei, Yubei, Yuzhong, Wulong and Changshou area as an example, the number of students is about 150, 84, 224, 111 and 72, their physical education teachers are two. It's easy to find that it's of supply and demand contradiction for special sports talents by comparing the demand and supply situation of special sports teachers in Chongqing.

\subsection{Orientations for special-education schools physical education teachers}

From the training form, Chongqing's special physical education teachers most have experienced counties centralized training, about a month before mount guard. A few old teachers also experienced traditional training, called "Master train an apprentice". They directly go to the post for teaching after graduate. There about 11 people, accounting $27 \%$ of the total.

From the training content, pre-service training mainly include teachers' adaptability of psychological training, language training, basic principle and method of special education etc. And the account for professional sports skill teaching and health care rehabilitation training is not big. Investigating its reason, mainly composed of two: one is that the subject classification of pre-service training is obscure, the adaptability education and basic teaching skills are in the majority, professional sports skills training proportion is reduced; The other is that special language communication (Braille, sign language) also accounts for a larger proportion.

From the subject of training, the difference between regions is apparent and their training abilities are uneven. The survey found that special teachers' pre-service training is counties centralized training basically, the same as general education teachers. Due to the differences of geographical location, economic development level, investment in education, leader's concept and so on, the starting line of sports teachers' orientation is varies significantly. Setting the deaf-mute school in Yuzhong as an example, the orientation for teachers, including sports teachers, is more systematized than other remote areas.

Summarized the above, it's needed to increase some courses about psychology measurement evaluation diagnose, health care and rehabilitation etc. In addition, a month for orientation, new teacher' evaluation is incomprehensive. It's bad for teachers' confidence and satisfaction. By the way of "pass, side, belt" to impart teaching experience to new teachers, is also influenced to make growth plans for them.

\subsection{In-service training for special-education schools physical education teachers}

\subsubsection{The forms of in-service training}

The forms of Sports teachers' in-service training mainly include three types: short-term training, course discussion and in-service education for further study. And the course discussion is of public class communication, exchange and research etc forms.

\subsubsection{The contents of in-service training}

It is found that the contents of the short-term training mainly include basic principle and technique of special education, communication skills and health care rehabilitation. Sports teaching method, ideology and morality account small percentage (figure1).Teachers' professional accomplishment comes from the teaching effect mostly, so it is of great significance to improve pertinence for training courses. Meanwhile it can not be ignored to strengthen education about vocational thought due to the special teaching environment.
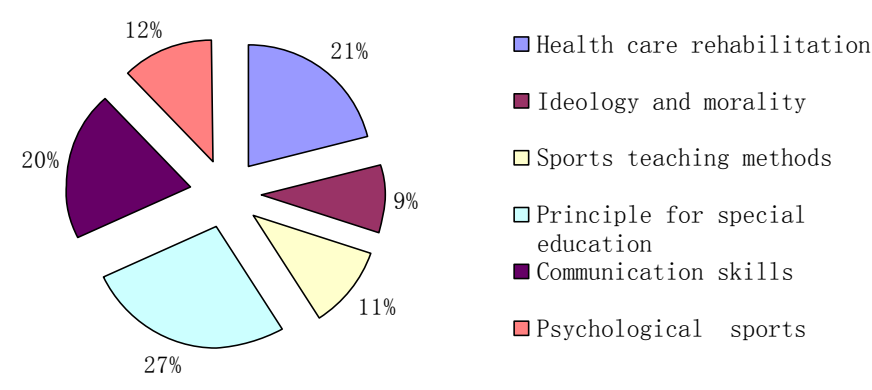

Fig.1 The contents for special sports teachers' short-term training

There are a lot of "part-time" teachers. And the depth of communication only stays in aspects as the organization form and content design for teaching. The goal of special schools sports and school-based curriculum development is not involved basically.

Sports teachers who receive education continually are more likely to major in special education than physical education. It is related to the proportion of part-time sports teachers.

\subsubsection{The frequency of in-service training}

Only seven people participated in the short-term training in recent weeks among 42 surveyed teachers; The proportion of teachers who participated in the training three months ago accounted for $23.8 \%$ of the total, about 10 people; More than eight people participated six months ago; Three people participated one or two years ago; Seven people was trained, before three years or more, the specific situation in figure 2 . 


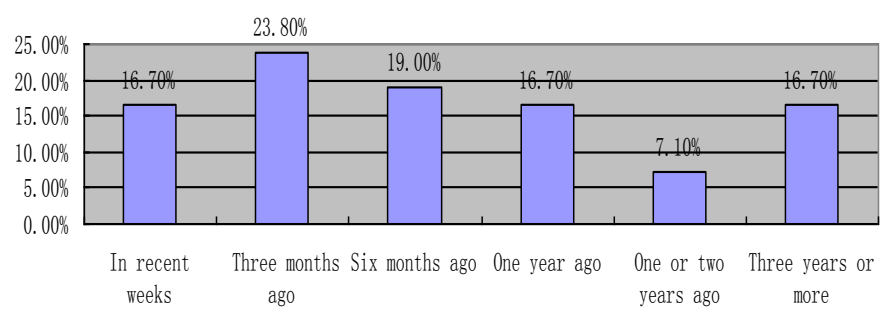

Fig.2 The frequency for special sports teachers' short-term training

Communication about public class and courses research which distribute in special and general education schools held more frequently than short-term training. But there must be clear, many teachers surveyed are not designed to teach sports, the conclusion above may be mixed with other courses' communication.

The proportion of teachers who received education continually in recent three years accounted for $23.8 \%$ of the total, about 10 people. Most of them have worked for five years.

\section{The Conclusions and Suggestions}

\subsection{The conclusions}

4.1.1 The cultivation of Chongqing special-education sports talents, so as to pre-service training, is in the supply and demand contradiction. Many of the teachers surveyed are on "part-time" jobs and graduates from special education and physical speciality couldn't master sports teaching skills well.

4.1.2 The orientation for special sports teachers is of overgeneralization. The contents of orientation are lack of targeted which are similar to general education teachers in a large degree. And a month for orientation, the evaluation for new teachers is incomprehensive.

4.1.3 The depth of the in-service training is not enough. Though the three forms about short-term training, course exploring and on-the-job degree guarantees the surface of teacher 'training, but not really into the key points, such as the goal of special schools sports and school-based curriculum development.

4.1.4 The level of vocational training integration for special physical education teachers is not high. The coherence of teacher's cultivation, orientation and in-service training is weak. It is always supposed that special sports talents have qualified all the skills for teaching and then The orientation and in-service training are lack of targeted.

\subsection{The suggestions}

4.2.1 Offer special physical education curriculum in Chongqing' normal universities and sports universities and colleges.

To meet the needs for special sports teachers in Chongqing and the whole region of southwest, it is necessary to offer special physical education curriculum in Chongqing' normal universities and sports universities and colleges. For normal universities, courses like exercise physiology, ball games for the disabled, the evaluation theory and method of fitness, movement trauma, etc can be considered. And the introduction to the basic theory of TCM, track and field sports for the disabled, rehabilitation, medical supervision, and the Chinese sign language could be important references for sports universities and colleges. Meanwhile, pay enough attention to the professional ideal and emotional education in all the stages of teachers' training is also much needed.

4.2.2 Reform orientation system; optimize the evaluation system of new teachers.

To enhance the pertinence of teachers' orientation, we advice to reform the orientation system form it's time and forms. XiaoJuMei, who is teaching for Hunan normal university, has put that the orientation of new teachers best to last for three semesters, gap is allowed in the process, but it should be completed within five years after the beginning. And it must to implement the two main contents all through: to supervise and support for new teachers, and to evaluate the performance of the teachers [3].The evaluation of the orientation is regarded as an important link in Britain. They would conduct formal assessment for three times, at the end of each semester respectively [4]. It is of great reference for special sports teacher to receive orientation above.

For the forms, "An example model" is called for to build. It's to select three special schools in Chongqing which is form visual impairment, hearing impairment and mental disorder respectively. And all of them are of a good reputation. New sports teachers need to receive training from each of these schools for half a month on the basis of the one month's orientation conducted by their countries. The train is better to complete in three years after new teachers go to their post formally.

4.2.3 Deepen the level of in-service training; provide opportunities for off-job learning.

It is necessary to increase the research about the goals of special sports education and school-based curriculum development. With more and more attention about special sports teaching, schools should try their best to realize the change of modern education concept.At the same time, Education promotion is an important approach to primary and secondary school teachers to achieve standard also. The training in Britain is divided into full-time block release; Part time day release and Spare not block release. Block release can be approved just for the teachers with more than 5 years' experience and the pass rate is about 30\%[5]. Our government can gain enlightenment from the policy and to provide teachers with five years experience for 1 semester' block release .So the teacher would not only regard the in-service education as a kind of obligation, also as a right to enjoy them.

4.2.4 Enhance the level of integration of teachers' vocational training.

To improve the level of integration for teachers' training, the contents in all the stages need to be designed effectively. Nowadays, the professional of special sports education has 
been set up in five schools in China and it can be say that the cultivation program of the speciality has been established already. But to the grogram of orientation and in-service training, we owned instructions only, which was similar to general education, hasn't detailed to the plan and contents. Therefore, the ministry of education should formulate the plans about teachers' pre-service training and in-service training as soon as possible.

\section{References}

[1] Gu fengmei. The current situation of special education school' sports teachers in Beijing. Journal of capital institute of physical education.2008, (5):3-4.
[2] Ye liuqing. The research and practice of integration for mathematics teachers' pre-service education in junior middle schools: In: The academic essays of the college mathematics education: national mathematics academic convention.2006, pp.539-540.

[3] Xiao jumei, and Xiao xiaoying. Orientation - a new important way of teacher professional development. Continue to education research.2003, (1):72-73.

[4] Yi hongjun. The level of teacher's training integration and it's characteristics in Britain. Higher normal education research.2003, 15 (4):77-78

[5] Su lina. The characteristics of teachers' in-service education in Britain and its enlightenment to China. Cultural and educational information. 2009, (11):92-93. 